\title{
Leukemia Inhibitory Factor and Ciliary Neurotrophic Factor Cause Dendritic Retraction in Cultured Rat Sympathetic Neurons
}

\author{
Xin Guo, ${ }^{1}$ Vidya Chandrasekaran, ${ }^{1}$ Pamela Lein, ${ }^{2}$ Paul L. Kaplan, ${ }^{3}$ and Dennis Higgins ${ }^{1}$ \\ ${ }^{1}$ Department of Pharmacology and Toxicology, State University of New York, Buffalo, New York 14214, 2 Department of \\ Biology, Canisius College, Buffalo, New York 14208, and ${ }^{3}$ Creative Biomolecules, Inc., Hopkinton, Massachusetts 01748
}

\begin{abstract}
Dendritic retraction occurs in many regions of the developing brain and also after neural injury. However, the molecules that regulate this important regressive process remain largely unknown. Our data indicate that leukemia inhibitory factor (LIF) and ciliary neurotrophic factor (CNTF) cause sympathetic neurons to retract their dendrites in vitro, ultimately leading to an $\sim 80 \%$ reduction in the size of the arbor. The dendritic retraction induced by LIF exhibited substantial specificity because it was not accompanied by changes in cell number, in the rate of axonal growth, or in the expression of axonal cytoskeletal elements. An antibody to gp130 blocked the effects of LIF and
\end{abstract}

Dendritic retraction takes many forms in the developing nervous system. In the magnocellular nucleus of chick embryos, neurons initially extend several long, branched dendrites. They then retract all of these processes as they become unipolar (Jhaveri and Morest, 1982). Purkinje cells also extend multiple primary dendrites; however, only the apical process survives, allowing these cells to assume their characteristic shape (Armengol and Sotelo, 1991). In other cases, dendritic regression is less dramatic, but the consequences are still important. For example, all the pyramidal cells in layer 5 of the visual cortex initially form apical dendrites that extend to layer 1 (Koester and O'Leary, 1992). However, as they mature, neurons whose axons have entered the corpus callosum retract the segments of their dendrite that contact the three most superficial cortical layers, thereby becoming short pyramidal cells. In contrast, neurons that send their axons to the tectum do not experience regression of the apical process and so become tall cells. Because different afferent fibers course through the various cortical layers, it is thought that this differential retraction leads to alterations in synaptic function. Dendritic retraction also occurs in many other parts of the developing brain, including the hippocampus (Rihn and Claiborne, 1990), lateral geniculate nucleus (Leuba and Garey, 1984), and autonomic ganglia (Landmesser and Pilar, 1974). In addition, dendritic atrophy has been observed during normal aging (Flood, 1993), in degenerative conditions, including Alzheimer's (Flood and Coleman, 1990) and Parkinson's diseases (Patt et al., 1991), and after acute neural injury (Sumner and Watson, 1971; Yawo, 1987). Thus, regressive events within dendritic processes are widespread, and they are important determinants of neuronal cell shape and synaptic connectivity.

\footnotetext{
Received Sept. 21, 1998; revised Dec. 29, 1998; accepted Dec. 29, 1998.

This work was supported by a grant from the National Science Foundation (D.H.). Correspondence should be addressed to Dr. Dennis Higgins, Department of Pharmacology and Toxicology, 102 Farber Hall, State University of New York, Buffalo, NY 14214

Copyright (C) 1999 Society for Neuroscience $\quad 0270-6474 / 99 / 192113-09 \$ 05.00 / 0$
}

CNTF, and both cytokines induced phosphorylation and nuclear translocation of stat3. Moreover, addition of soluble interleukin-6 (IL-6) receptor to the medium endowed IL-6 with the ability to cause dendritic regression. These data indicate that ligands activating the gp130 pathway have the ability to profoundly alter neuronal cell shape and polarity by selectively causing the retraction of dendrites.

Key words: leukemia inhibitory factor; ciliary neurotrophic factor; osteogenic protein-1; bone morphogenetic protein; dendritic retraction; dendrites; sympathetic neurons; stat3; gp130

Several studies suggest that deprivation of target-derived growth factors contributes to the dendritic retraction that is induced by axotomy (Yawo, 1987; Purves et al., 1988; Snider, 1988). In addition, excitatory amino acids such as glutamate have been found to cause dendritic retraction in some types of cultured neurons (Metzger et al., 1998), and there is evidence that these neurotransmitters are involved in certain forms of injury and stress-induced dendritic regression in vivo (McEwen and Magarinos, 1997). These observations suggest that there may be multiple pathways that produce dendritic atrophy. However, mediators of dendritic retraction have been identified in only a limited number of systems, and so in most instances we do not know which molecules regulate this important regressive process.

Leukemia inhibitory factor (LIF) and ciliary neurotrophic factor (CNTF) belong to the neuropoietic family of cytokines; other family members include interleukin-6 (IL-6), IL-11, oncostatin-M (OSM), and cardiotrophin-1 (Patterson, 1994). Neuropoietic cytokines are expressed in many regions of the nervous system, as are their receptors. Sympathetic neurons are one of the classes of neurons that express receptors for these cytokines, and it is known that they are exposed to several family members, both during their development and after neural injury. This has led to the use of these neurons as a model system for analyzing the effects of neuropoietic cytokines (Patterson, 1994; Landis, 1996; Zigmond et al., 1996; Mehler and Kessler, 1997). The response of sympathetic neurons to these agents is complex and includes changes in the neurotransmitter phenotype as well as in cell survival and the expression of transmitter receptors. In addition, it has previously been observed (Guo et al., 1997) that neuropoietic cytokines inhibit the initial extension of dendritic processes in cultures of sympathetic neurons that have been treated with osteogenic protein-1 [(OP-1) also known as bone morphogenetic protein-7]. In this study, we extend these observations by examining the effects of LIF and related cytokines on existing dendrites. Our data indicate that LIF and CNTF have the ability to 
selectively modify the shape of sympathetic neurons by inducing the retraction of dendritic, but not axonal, processes. These data suggest a novel morphogenetic role for neuropoietic cytokines.

There is substantial evidence that the trophic and differentiation-inducing effects of neuropoietic cytokines are mediated by the gp130/stat pathway, acting either alone or sometimes in conjunction with other cascades (Ip and Yancopoulous, 1996: Segal and Greenberg, 1996). In contrast, little is known about the signaling mechanisms that are involved in their regressive effects on neurons. In fact, the only previously described regressive activity of this class of growth factors on neurons has been the induction of cell death in immature sympathetic cells (Kessler et al., 1993; Kotzbauer et al., 1994). This study examines the pathway mediating cytokine-induced dendritic retraction and provides evidence that it too involves gp130 and stat3. Thus, in contrast to the neurotrophins that use two distinct classes of receptors to influence sympathetic neurons (Carter and Lewin, 1997), the neuropoietic cytokines appear to use a single pathway to influence survival, differentiation, and process regression in these cells.

\section{MATERIALS AND METHODS}

Materials. Recombinant human OP-1 was isolated from medium conditioned by transfected Chinese hamster ovary cells using S-Sepharose and phenyl-Sepharose chromatography followed by RP-HPLC (Sampath et al., 1992). Recombinant human LIF, IL-11, OSM, and murine monoclonal antibody to gp130 (MAB 228) were purchased from R\&D Systems (Minneapolis, MN). CNTF, cardiotrophin-1, and IL-6 were purchased from PeproTech (Rocky Hill, NJ), and soluble IL-6 receptor fragment (sIL-6R) and phosphatidylinositol-phospholipase C (PI-PLC) were from Sigma (St. Louis, MO).

Tissue culture. Sympathetic neurons dissociated from the superior cervical ganglia of perinatal (embryonic day 21 or 1-2 d postnatal) Holtzman rats (Harlan Sprague Dawley, Rockford, IL) were prepared using previously described methods (Higgins et al., 1991). Cells were plated onto poly-D-lysine-coated coverslips and maintained in a serumfree medium containing $\beta$-nerve growth factor (NGF, $100 \mathrm{ng} / \mathrm{ml}$ ). Cytosine- $\beta$-D-arabinof uranoside $(1 \mu \mathrm{M})$ was added to the medium of all cultures for $48 \mathrm{hr}$ beginning on day 2. Experimental treatments were begun on the fifth or sixth day in vitro, after non-neuronal cells had been eliminated.

Morphological analyses. Cellular morphology was assessed by the intracellular injection of fluorescent dyes [4\% Lucifer yellow or 5\% 5(6)carboxyfluorescein] and by immunocytochemistry. Cultures were immunostained with monoclonal antibodies (mAbs) previously shown to react selectively with dendrites of sympathetic neurons (Lein et al., 1995; Guo et al., 1997); these included mAbs to MAP2 (AP20, Sigma; SMI-52, Sternberger Immunocytochemicals, Baltimore, MD) and to nonphosphorylated forms of the $\mathrm{M}$ and $\mathrm{H}$ neurofilament subunits (SMI-32, Sternberger Immunocytochemicals). All antigens were localized by indirect immunofluorescence using previously described procedures (Lein et al., 1995). Process length was assessed using Metamorph Software (Universal Imaging, West Chester, PA).

The cellular distribution of the phosphorylated stat 3 was visualized by confocal microscopy after cultures had been immunostained with a rabbit polyclonal antibody (New England Biolabs, Beverly, MA) that specifically reacts with stat 3 phosphorylated on Tyr705. Confocal images were collected at a section thickness of $1 \mu \mathrm{m}$ using a Bio-Rad MRC 1000 laser scanning confocal microscope (Bio-Rad, Hercules, CA).

Western blotting analyses. To examine the expression of cytoskeletal proteins and phosphorylated stat 3 , sympathetic neurons were plated onto polylysine-coated $35 \mathrm{~mm}$ dishes and treated with growth factors for varying amounts of time. Cells were then harvested in $50 \mathrm{~mm}$ Tris buffer, $\mathrm{pH} 7.4$, containing $0.1 \%$ SDS, $2 \%$ 2-mercaptoethanol, and 1 mM EDTA, and homogenized by passaging through a 23 gauge needle at $4^{\circ} \mathrm{C}$. Cell extracts were boiled for $5 \mathrm{~min}$ and centrif uged at $12,000 \times \mathrm{g}$ for $15 \mathrm{~min}$. The protein concentration of the various supernatants was determined using the Bradford dye reagent (Bio-Rad). Equal amounts of proteins were analyzed by SDS-PAGE. Subsequently proteins were electrophoretically transferred to a nitrocellulose membrane and probed with mAbs (AP20 or SMI-52) to MAP2, mAb to $\beta$-tubulin (a gift from Dr.
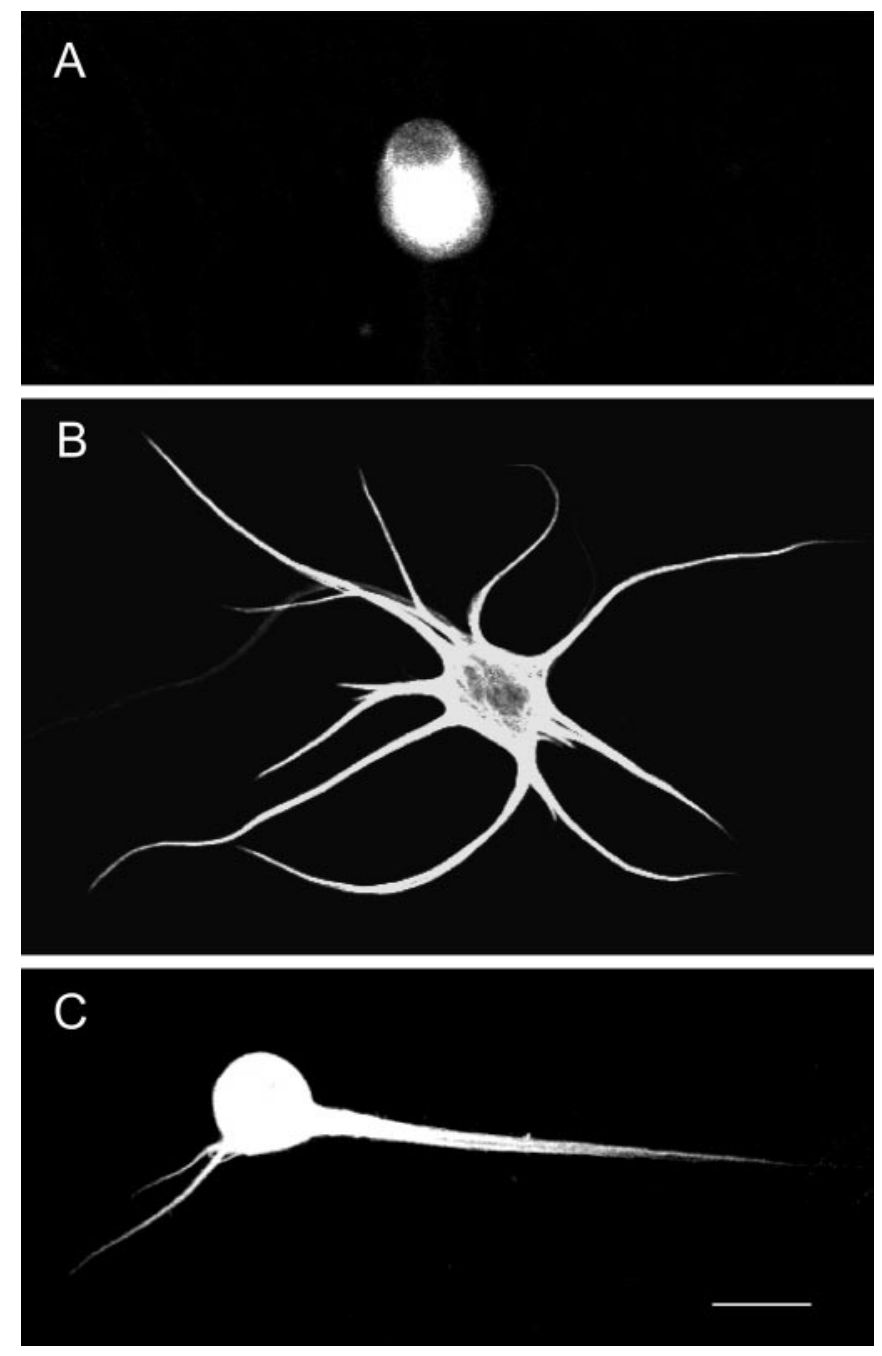

Figure 1. Effects of OP-1 and LIF on sympathetic neurons. A, Fluorescence micrograph of a sympathetic neuron that was grown under control conditions before being immunostained with a mAb (SMI52) to MAP2. Such cells typically lacked dendrites, whereas cells that had been treated with OP-1 $(50 \mathrm{ng} / \mathrm{ml})$ for $15 \mathrm{~d}(B)$ had complex arbors. $C$, The size of the dendritic arbor was reduced when cells that had initially been treated with OP-1 for $12 \mathrm{~d}$ were treated for an additional $3 \mathrm{~d}$ with the combination of LIF (10 $\mathrm{ng} / \mathrm{ml})$ and OP-1. Scale bar, $50 \mu \mathrm{m}$.

Robert Hard, University of Buffalo, Buffalo, NY), mAb to the phosphorylated forms of the $\mathrm{H}$ and $\mathrm{M}$ neurofilament subunits (SMI-31, Sternberger Immunocytochemicals), and polyclonal antiserum to the phosphorylated form of stat3. Detection was accomplished using Chemiluminescent Substrate (Pierce Chemical, Rockford, IL) after sequential treatment with biotinylated goat anti-mouse $\mathrm{IgG}$ (HyClone Laboratories, Logan, UT) and horseradish peroxidase-conjugated streptavidin (Amersham, Arlington Heights, IL).

\section{RESULTS}

\section{LIF and CNTF induce dendritic retraction}

Sympathetic neurons were maintained in a serum-free medium and experimental treatments were begun on the fifth day in vitro, after non-neuronal cells had been eliminated. In agreement with previous observations (Lein et al., 1995), it was found that OP-1 induces dendritic growth in these cells (Fig. 1) and that the number of dendrites formed during a 2 week exposure to OP-1 $(6.8 \pm 0.4$ dendrites/cell) closely approximates the number (6.9 

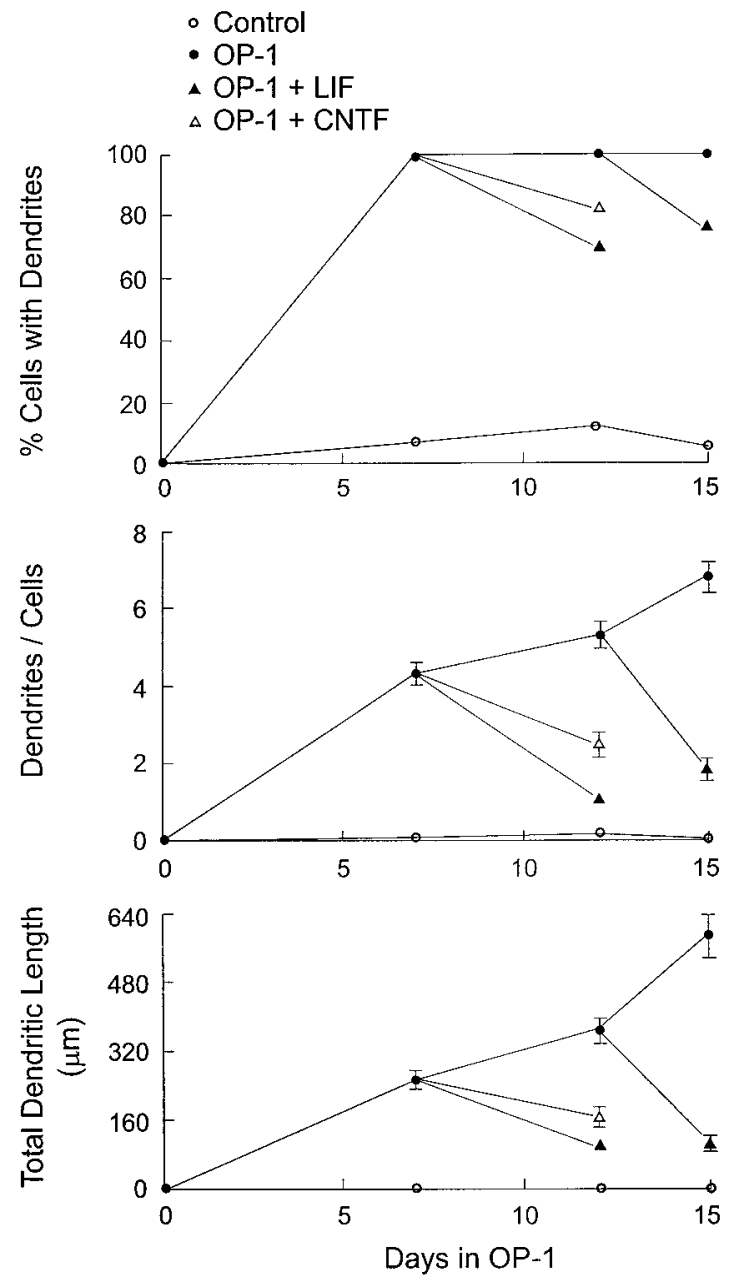

Figure 2. Time course of LIF- and CNTF-induced dendritic retraction in sympathetic neurons. Sympathetic neurons were plated onto polylysine-coated coverslips, and non-neuronal cells were eliminated by a $2 \mathrm{~d}$ exposure to an antimitotic agent. Cultures were then continuously treated with OP-1 $(50 \mathrm{ng} / \mathrm{ml})$. On day 7 or 12 , some OP-1-treated cultures were also exposed to either LIF (30 ng/ml) or CNTF (30 ng/ml) for 3-5 d. Cellular morphology was analyzed after cultures had been immunostained with an mAb (SMI-52) to MAP2. Data are expressed as mean \pm $\operatorname{SEM}(n=30)$.

dendrites/cell) arising from sympathetic neurons of 2-week-old rats in situ (Snider, 1988). Similarly, the size of the dendritic arbor (total linear length of $590 \pm 50 \mu \mathrm{m} /$ cell) generated during this period in vitro was $\sim 75 \%$ the size of that observed in vivo.

To assess the effects of LIF on existing dendritic processes, neurons were initially exposed to OP-1 for $12 \mathrm{~d}$. Subsequently they were treated for an additional $3 \mathrm{~d}$ with either OP-1 alone or with the combination of both LIF and OP-1. On the 15th day, cultures were immunostained with an antibody to MAP2, and it was found that the neurons that had been treated with both LIF and OP-1 had fewer dendrites and smaller arbors than the cells exposed to OP-1 alone (Figs. 1, 2). These data indicate that LIF inhibits the growth of existing dendrites. It was also found that neurons that had been exposed to LIF and OP-1 on days 13-15 had smaller arbors than neurons that had been stained after $12 \mathrm{~d}$ of OP-1 treatment, indicating that LIF also causes the retraction of existing processes. The LIF-induced decrease in the size of the arbor reflected a reduction both in the number of primary dendrites (Fig. 2) and in the length of the individual processes (data

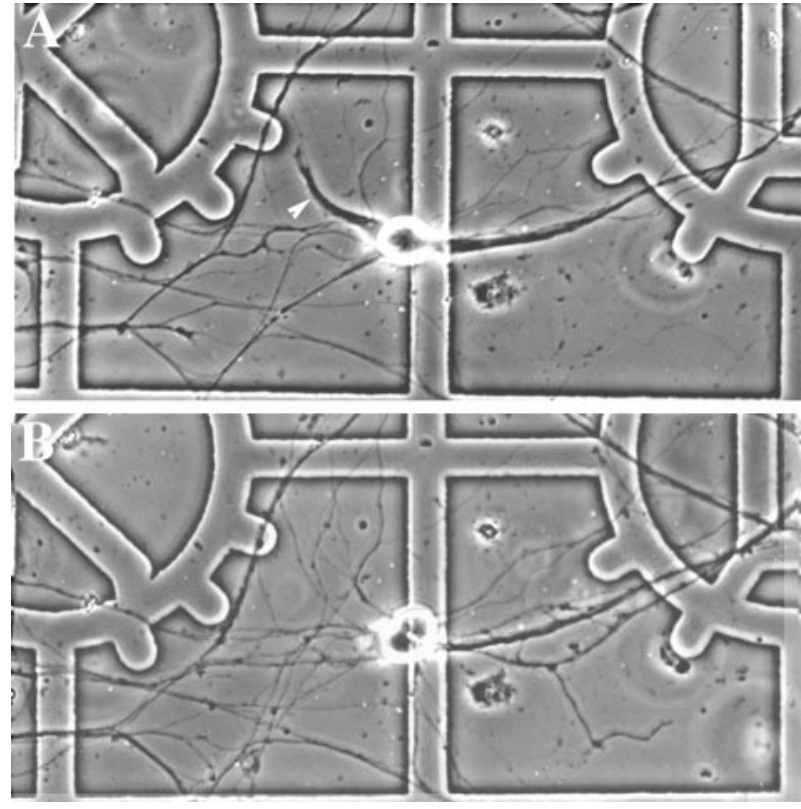

Figure 3. Serial observations of the effects of LIF on neuronal morphology. $A$, Phase-contrast image of a sympathetic neuron's that had been treated with OP-1 $(50 \mathrm{ng} / \mathrm{ml})$ for $4 \mathrm{~d}$. One of this neuron's dendrites (arrowhead) could be examined in its entirety because it grew through an area where there were only a few axons. The cell was then treated with LIF (10 ng/ml) and OP-1 for $2 \mathrm{~d}$. When the neuron was relocated $(B)$, it was found that the dendrite had retracted. In contrast, the density of the axonal plexus increased and new processes appeared (bottom right and left). Note that the cell shown in $A$ has a second, thick dendrite-like process that arises from the right side of the cell and that this process is associated with a bundle of axons. Such fasciculated processes were excluded from our analysis because we could not accurately determine where they ended.

not shown). Exposure to LIF also caused a $25 \%$ decrease in the percentage of cells with dendrites (Fig. 2), indicating that many neurons eliminated all of these processes.

The data in Figures 1 and 2 were obtained from cultures that had been immunostained with antibody to MAP2. However, similar results were obtained when cellular morphology was analyzed by intracellular dye injection or by immunostaining with another dendritic marker, antibody to nonphosphorylated forms of the $\mathrm{M}$ and $\mathrm{H}$ neurofilament subunits (data not shown). Thus, the effects of LIF reflect actual process elimination rather than the loss of MAP2 from distal dendrites.

LIF-induced dendritic retraction was also observed in cultures of perinatal neurons that had been treated with OP-1 for 4 (Fig. 3), 7 (Fig. 2), and 27 (data not shown) d, and the magnitude of the decrease in the extent of the dendritic arbor $(83,73$, and $75 \%$, respectively) was similar to that observed in the aforementioned $12 \mathrm{~d}$ cultures $(82 \%)$. LIF also caused dendritic retraction in cultures of adult sympathetic neurons that had been treated with OP-1 for $7 \mathrm{~d}$ (data not shown). Thus, it appears that the effects of LIF on dendritic growth remain relatively constant in nature and magnitude during development.

\section{Serial observations of LIF-treated dendrites}

The response to LIF was further characterized by examining its effects on the behavior of individual processes. Sympathetic neurons were plated at low density onto gridded coverslips and then treated with OP-1. Under these conditions, it was often possible to visualize individual dendrites of these neurons in their entirety 

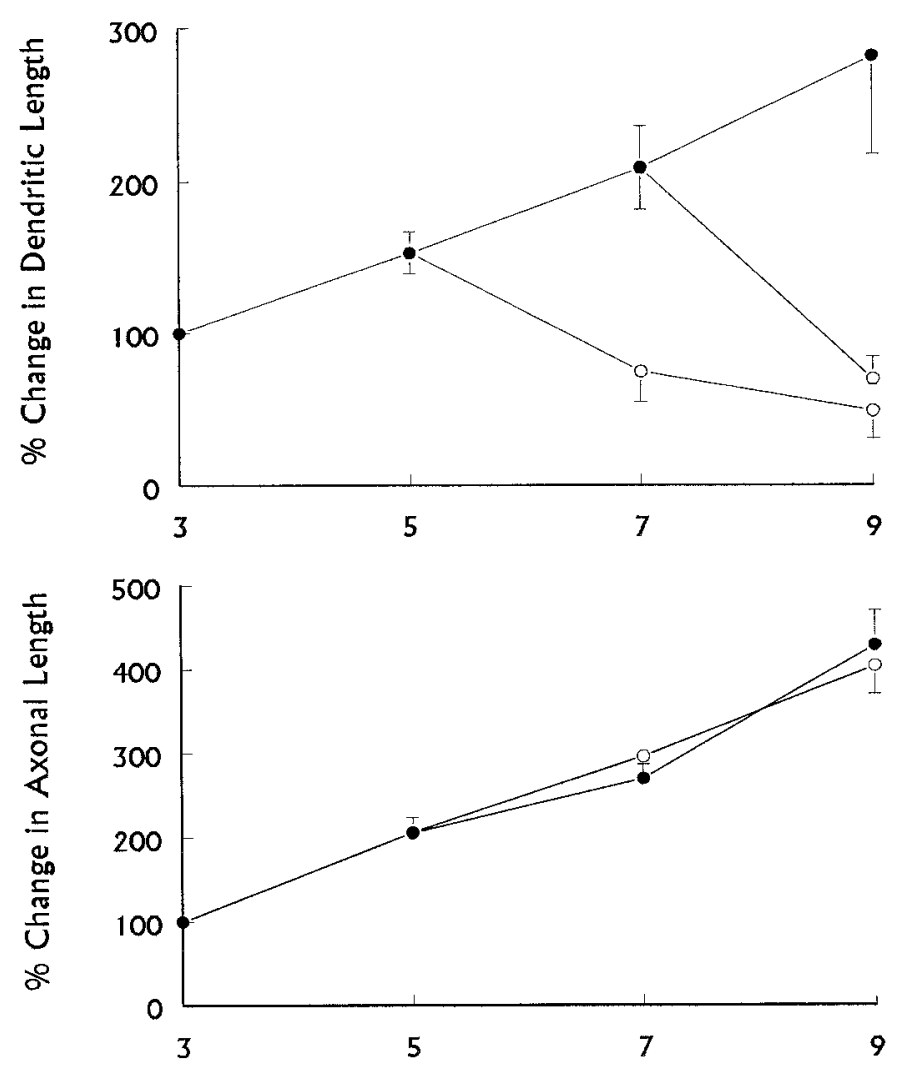

Days in OP-1

Figure 4. Comparison of changes in dendritic and axonal length during LIF-induced dendritic retraction. Sympathetic neurons were plated onto gridded coverslips and exposed to OP-1 $(\bullet, 50 \mathrm{ng} / \mathrm{ml})$ for a total of $9 \mathrm{~d}$. On days 5 and 7 , some cultures were also exposed to $\operatorname{LIF}(\bigcirc, 30 \mathrm{ng} / \mathrm{ml})$. Identified cells or regions on the grid were photographed daily to allow quantitation of dendritic or axonal growth, respectively. Mean \pm SEM $(n=5-12)$.

(Fig. 3), and our experiments focused on such isolated processes. These processes could be distinguished from axons by light microscope criteria such as their diameter, taper, and branching patterns, and the identity was confirmed in many instances by dye injection.

LIF treatment was begun on the fourth day of OP-1 exposure, and cellular morphology was compared at $1 \mathrm{~d}$ intervals. In control cultures treated with OP-1 alone, most dendrites (76\%) increased in length, and the remainder $(24 \%)$ showed no change during the first $24 \mathrm{hr}$ period. In contrast, in cultures treated with the combination of OP-1 and LIF, only $8 \%$ of the dendrites elongated during the first day, whereas $73 \%$ exhibited no net change in length and $18 \%$ underwent retraction. During the second day of exposure to LIF and OP-1, however, the nature of the response began to change: the percentage of dendrites undergoing retraction $(43 \%)$ rose sharply, whereas the number of elongating dendrites $(2 \%)$ fell further. It thus appears that the initial response to LIF is an arrest of growth and that several days of exposure to LIF are required to induce retraction in most dendrites.

Serial imaging revealed that although cell bodies became rounded as dendrites retracted, the LIF-treated neurons appeared to be healthy (Fig. 3), and cell number remained constant (data not shown). Moreover, it appeared that axons continued to elongate and generate a more elaborate plexus during LIF treat- ment. To quantify the changes in axonal length, the amount of axonal growth that occurred in selected areas on gridded coverslips was examined. Images were recorded after $3 \mathrm{~d}$ of exposure to OP-1 and again after an additional $4 \mathrm{~d}$ exposure to OP-1 or the combination of OP-1 and LIF. Axonal growth was observed in both groups, and the rate of increase was equivalent in cultures treated with OP-1 alone or OP-1 plus LIF (Fig. 4). In contrast, the size of the dendritic arbor was significantly reduced in cultures treated with both OP-1 and LIF as compared with cultures treated with OP-1 alone (Fig. 4). It therefore appears that LIF affects sympathetic neurons in a process-specific manner by selectively modifying the growth of dendrites but not axons. Consistent with this hypothesis, it was found that treatment with LIF decreased the expression of MAP2, a protein found primarily in dendrites, without affecting the expression of phosphorylated forms of the neurofilament $\mathrm{H}$ and $\mathrm{M}$ subunits, which are primarily axonal proteins (Fig. 5), or $\beta$-tubulin, which is distributed throughout the cell.

\section{Concentration-effect relationships and comparison of LIF with other cytokines}

Dendritic retraction increased with exposure to greater concentrations of LIF (Fig. 6). Maximum dendritic retraction was observed with concentrations between 10 and $30 \mathrm{ng} / \mathrm{ml}$. The $\mathrm{IC}_{50}$ value for LIF-induced dendritic retraction was $\sim 0.3 \mathrm{ng} / \mathrm{ml}$, and significant changes in dendritic morphology could be detected with concentrations as low as $0.01 \mathrm{ng} / \mathrm{ml}$.

To determine whether other members of the IL-6 family of cytokines also induce dendritic retraction in sympathetic neurons, we compared the effects of LIF with those of CNTF, IL-6, IL-11, and OSM. CNTF (Fig. 2) and cardiotrophin-1 (data not shown) consistently induced dendritic retraction, and in most experiments their effects were equivalent in magnitude to those

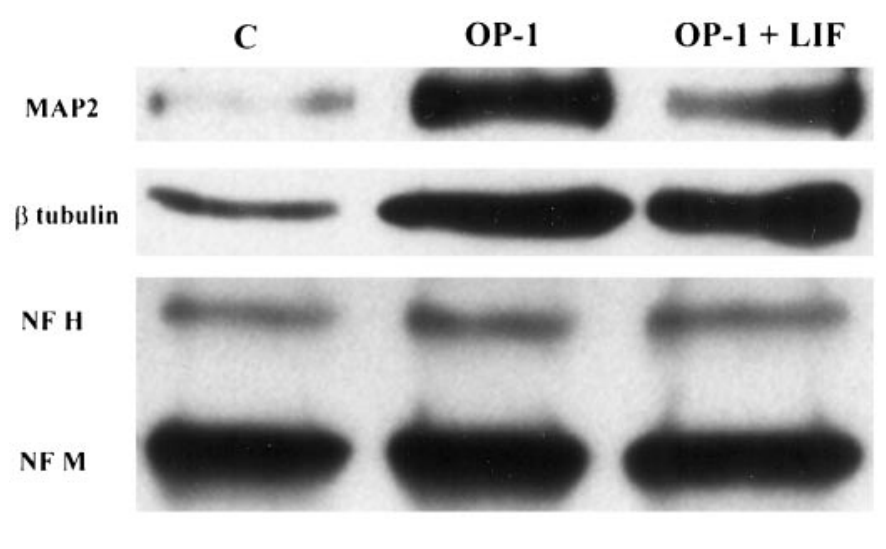

Figure 5. LIF decreases OP-1-induced MAP2 expression. Cultures were exposed to OP-1 $(50 \mathrm{ng} / \mathrm{ml})$ for $3 \mathrm{~d}$ and then treated with either OP-1 alone or OP-1 + LIF $(30 \mathrm{ng} / \mathrm{ml})$ for an additional $4 \mathrm{~d}$. Western blot analysis was performed to examine expression of MAP2 $(280 \mathrm{kDa})$, $\beta$-tubulin (53 kDa), and the phosphorylated forms of the $\mathrm{H}(200 \mathrm{kDa})$ and M (160 kDa) neurofilament subunits. The chemiluminescent autographs are representative of three experiments that yielded similar results. In these experiments there was $2.5 \pm 0.3$-fold increase in MAP2 expression in cultures treated with OP-1 ( $p<0.01$ vs control). This was reduced to a $1.4 \pm 0.2$-fold increase in cultures treated with LIF and OP-1, a value that was not significantly different from the control condition. Similarly, there were no significant changes detected in the expression of phosphorylated forms of the $\mathrm{M}$ and $\mathrm{H}$ neurofilament subunits under any of the experimental conditions. Exposure to OP-1 produced a $1.9 \pm 0.2$-fold increase in tubulin expression ( $p<0.01$ vs control), and this change was unaffected by concomitant exposure to LIF $(1.8 \pm 0.2$-fold increase over control). 


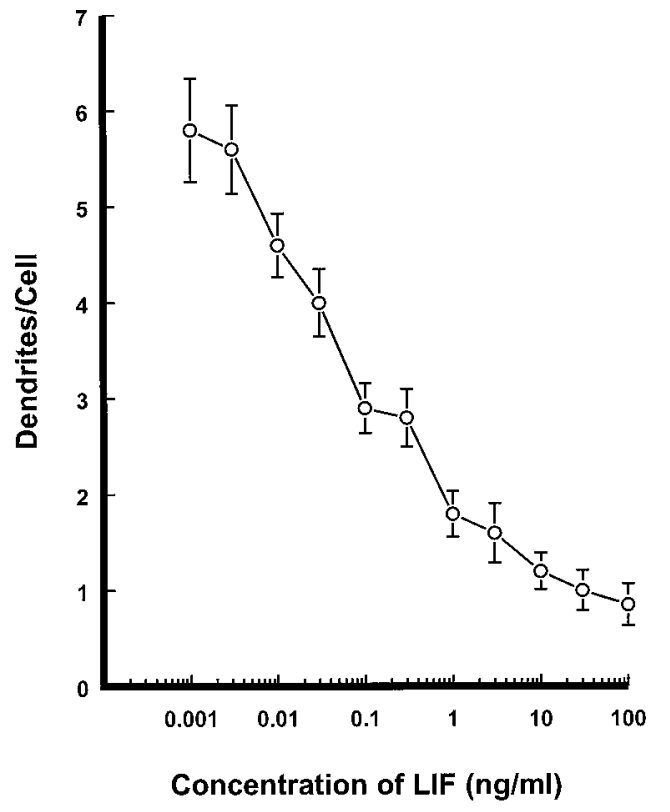

Figure 6. Concentration-effect relationship for LIF-induced dendritic retraction. Cultures of sympathetic neurons were exposed to OP-1 (50 $\mathrm{ng} / \mathrm{ml}$ ) for $3 \mathrm{~d}$ and then treated with OP-1 plus various concentrations of LIF for an additional $4 \mathrm{~d}$. The number of dendrites per cell was quantified after cultures had been immunostained with an $\mathrm{mAb}$ to the nonphosphorylated forms of the $\mathrm{H}$ and $\mathrm{M}$ neurofilament subunits. Mean \pm SEM $(n=30)$.

Table 1. Comparison of the effects of members of the IL-6 family of cytokines on dendritic retraction

\begin{tabular}{ll} 
Growth factor & Dendrites/cell \\
\hline OP-1 & $5.6 \pm 0.5$ \\
OP-1 + LIF & $1.1 \pm 0.3^{* *}$ \\
OP-1 + CNTF & $1.0 \pm 0.2^{* *}$ \\
OP-1 + IL-6 & $5.7 \pm 0.4$ \\
OP-1 + IL-11 & $5.3 \pm 0.4$ \\
OP-1 + OSM & $4.5 \pm 0.4^{*}$
\end{tabular}

Sympathetic cultures were plated onto polylysine-coated coverslips, and nonneuronal cells were eliminated by a $2 \mathrm{~d}$ exposure to antimitotic agent. For the next $3 \mathrm{~d}$, cultures were treated with $50 \mathrm{ng} / \mathrm{ml}$ OP-1. Subsequently they were exposed to OP-1 alone or in combination with $30 \mathrm{ng} / \mathrm{ml} \mathrm{LIF,} \mathrm{CNTF,} \mathrm{IL-6,} \mathrm{IL-11,} \mathrm{or} \mathrm{OSM} \mathrm{for}$ 5 d. Cellular morphology was analyzed after cultures had been immunostained with an $\mathrm{mAb}$ to the nonphosphorylated forms of the $\mathrm{H}$ and $\mathrm{M}$ neurofilament subunits. Mean $\pm \operatorname{SEM}(n=30) .{ }^{*} p<0.05$ and ${ }^{* *} p<0.001$ versus OP-1.

produced by LIF (Table 1). In contrast, IL-6 and IL-11 failed to induce dendritic retraction, and OSM had only weak effects at concentrations up to $30 \mathrm{ng} / \mathrm{ml}$.

\section{Involvement of the gp130 pathway in dendritic retraction}

Neuropoietic cytokines exert trophic effects on many types of neural cells, and most of these actions are mediated by the gp130/stat pathway (Ip and Yancopoulos, 1996; Segal and Greenberg, 1996). The finding that several members of this family also caused dendritic retraction suggested that the inhibitory effects of these agents might also be mediated by this pathway. Four experiments were performed to test this hypothesis.

The CNTF receptor complex is a heterotrimer consisting of gp130, the LIF receptor (LIFR), and CNTF receptor $\alpha$ subunit (CNTFR) (Ip and Yancopoulous, 1996; Segal and Greenberg,

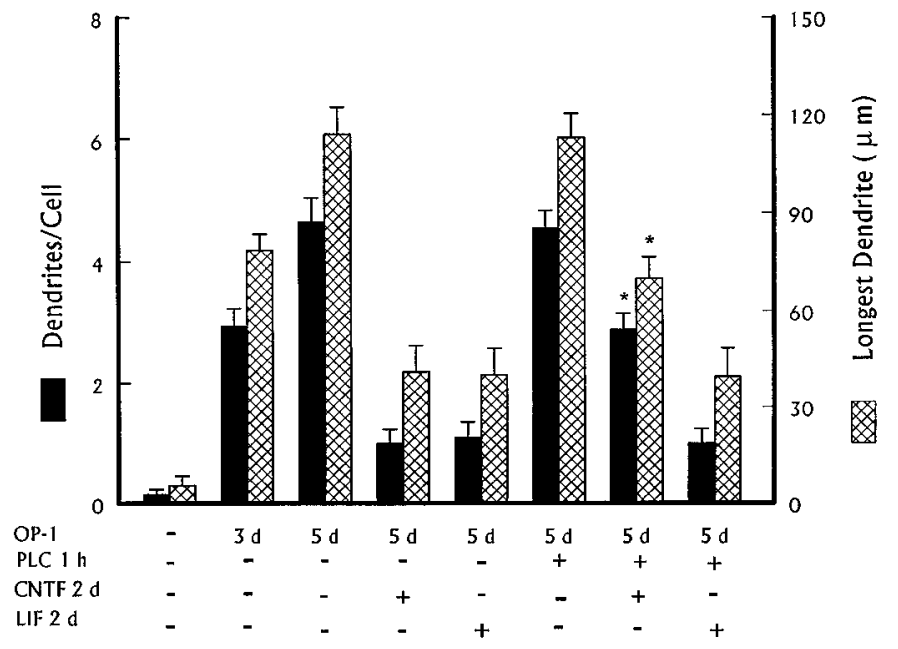

Figure 7. Treatment with PI-PLC reverses CNTF- but not LIF-induced dendritic retraction. Cultures of sympathetic neurons were exposed to OP-1 $(50 \mathrm{ng} / \mathrm{ml})$ for $3 \mathrm{~d}$. Subsequently, some cultures were exposed for an additional $2 \mathrm{~d}$ to OP- 1 combined with CNTF (30 ng/ml) or LIF (30 $\mathrm{ng} / \mathrm{ml})$. Other cultures were treated with PI-PLC $(1 \mathrm{U} / \mathrm{ml})$ for $1 \mathrm{hr}$ before receiving the aforementioned CNTF or LIF treatments. Cellular morphology was analyzed after immunostaining with an mAb to the nonphosphorylated forms of the $\mathrm{H}$ and $\mathrm{M}$ neurofilament subunits. Mean $\pm \mathrm{SEM}$ $(n=30) .{ }^{*} p<0.01$ versus OP- $1+$ CNTF.

1996). The CNTFR specifically confers CNTF responsiveness, and it is linked to the cell membrane via a glycosylphosphatidylinositol bond that can be cleaved by PI-PLC. In contrast, the two subunits (gp130 and LIFR) that are required for responsiveness to LIF are integral membrane proteins that are unaffected by this enzyme. An examination of the effects of PI-PLC treatment on the response of cells to these cytokines revealed that CNTFinduced dendritic retraction was reduced by previous PI-PLC treatment, whereas the response to LIF remained intact (Fig. 7). These results suggest that CNTF-induced dendritic retraction requires the intact $\mathrm{CNTF}$ receptor complex.

We next examined the effects of an antibody (MAB 228) to gp130 on cytokine-induced dendritic retraction (Table 2). In these experiments we used a concentration of LIF that produced a $39 \%$ decrease in the size of the dendritic arbor. A submaximal concentration of LIF was used because the interaction between MAB 228 and gp130 is influenced by the concentration of the ligand, and so inhibition of the LIF response was more apparent with concentrations near the $\mathrm{ED}_{50}$ as compared with higher concentrations. Under these conditions, antibody to gp130 signif-

\section{Table 2. Effects of antibody to gp130 on LIF-induced dendritic} retraction

\begin{tabular}{ll} 
Growth factor & Dendrites/cell \\
\hline OP-1 & $4.2 \pm 0.3$ \\
OP-1 + LIF & $2.6 \pm 0.3$ \\
OP-1 + LIF + anti-gp130 & $3.5 \pm 0.4^{*}$ \\
OP-1 + anti-gp130 & $4.2 \pm 0.3$
\end{tabular}

Cultures of sympathetic neurons were treated with OP-1 $(100 \mathrm{ng} / \mathrm{ml})$ for $5 \mathrm{~d}$ to induce dendritic growth. Beginning on the sixth day, LIF $(500 \mathrm{pg} / \mathrm{ml})$, antibody to gp130 (MAB 228, $100 \mu \mathrm{g} / \mathrm{ml}$ ), or both agents were added to the OP-1-containing medium of some cultures. Cellular morphology was assessed on the seventh day after immunostaining with antibody to nonphosphorylated forms of the $\mathrm{M}$ and $\mathrm{H}$ neurofilament subunits. ${ }^{*} p<0.05$ compared with OP-1 + LIF treatment. 


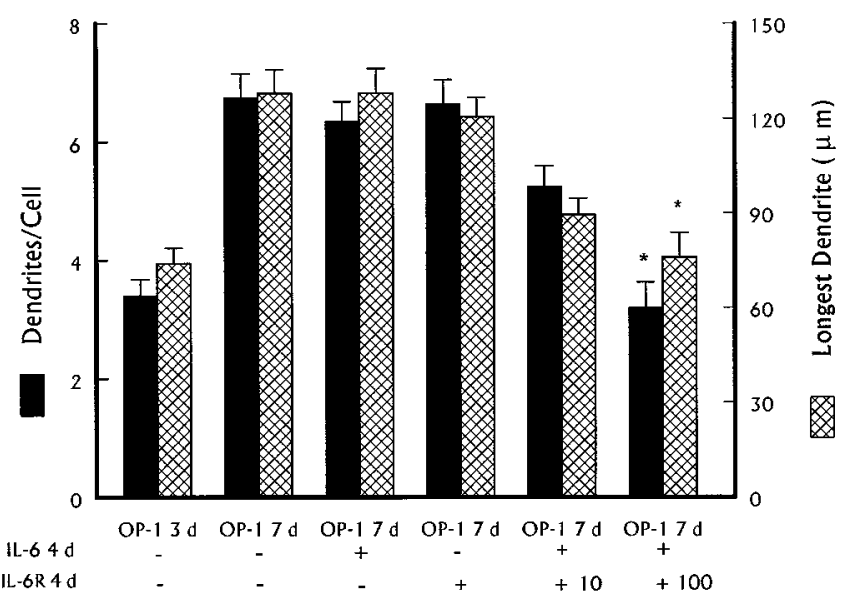

Figure 8. The effects of soluble IL-6 receptor $(s I L-6 R)$ on dendritic retraction. Cultures of sympathetic neurons were exposed to OP-1 (50 $\mathrm{ng} / \mathrm{ml})$ for $3 \mathrm{~d}$. Subsequently, cultures were treated with OP-1 + IL-6 (30 $\mathrm{ng} / \mathrm{ml})$, sIL-6R (100 ng/ml), or IL-6 + sIL-6R (10 or $100 \mathrm{ng} / \mathrm{ml})$ for an additional $4 \mathrm{~d}$. Cellular morphology was analyzed after immunostaining with a dendritic-specific antibody (SMI-32). Mean \pm SEM $(n=30) .{ }^{*} p<$ 0.01 versus OP-1 + IL-6.

icantly attenuated the dendritic retraction induced by either LIF (Table 2) or CNTF (data not shown).

The IL- 6 receptor complex is also a heterotrimer that consists of two gp130 subunits and a third subunit called IL-6R (Ip and Yancopoulous, 1996; Gadient and Otten, 1997). Because sympathetic neurons are known to express gp130 in culture, it seemed possible that the failure of these neurons to respond to IL-6 reflected a low level of expression of the IL-6R (Marz et al., 1998). This hypothesis was tested by adding back to cultures a recombinant soluble form of the IL-6R that is known to be capable of forming effective signaling complexes with gp130 (Saito et al., 1991; Marz et al., 1998). Neither IL-6 nor the soluble IL-6R alone had effects on dendritic morphology (Fig. 8). However, the combination of both proteins caused a profound inhibition of dendritic growth, in terms of both the number of dendrites per cell and total dendritic length.

Finally, the effects of neuropoietic cytokines on stat3, a transcription factor involved in gp130 signaling, were examined. Cultures of sympathetic neurons were exposed to OP-1 or the combination of OP-1 with LIF or IL-6 for 20 min. Cellular proteins were then harvested and immunoblotted with an antibody that reacts with the phosphorylated form of stat3. LIF, which is able to induce dendritic retraction, caused significant phosphorylation of stat3, whereas IL-6, which does not affect dendritic growth, was inactive (Fig. 9). Similarly, when cells were immunostained with this antibody, it was found that there was a prominent nuclear translocation of phosphorylated stat3 in LIF- or CNTF-treated cells and that this was absent in control or IL-6-treated cells (Fig. 10).

\section{DISCUSSION}

Many molecules have been shown to inhibit the growth of axons (Luo and Raper, 1994; Tessier-Lavigne and Goodman, 1996) and dendrites (Mattson, 1988; LaFont et al., 1994; Guo et al., 1997; McAllister et al., 1997). In contrast, less is known about the agents that cause neurons to eliminate existing processes (Snider and Lichtman, 1996). Our data indicate that LIF and CNTF cause sympathetic neurons to retract most of their dendrites. Cytokine-induced dendritic regression was observed in cultures

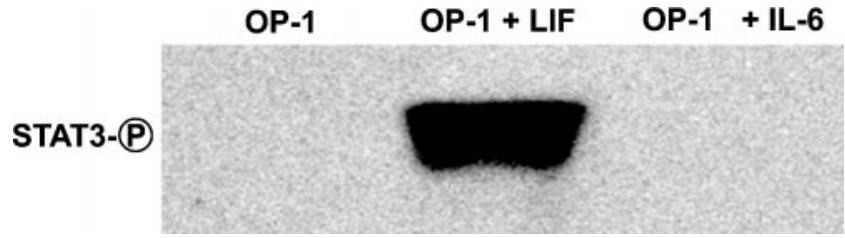

Figure 9. LIF induces phosphorylation of stat3. Cultures of sympathetic neurons were exposed to OP-1 for $3 \mathrm{~d}$ and then treated with either LIF $(30 \mathrm{ng} / \mathrm{ml})$ or IL-6 $(30 \mathrm{ng} / \mathrm{ml})$ for $20 \mathrm{~min}$. Cellular proteins were analyzed by Western blot using an antibody against the phosphorylated forms of stat3. Stat3 had an apparent molecular weight of $92 \mathrm{kDa}$. The chemiluminescent autographs are representative of three experiments that yielded similar results.
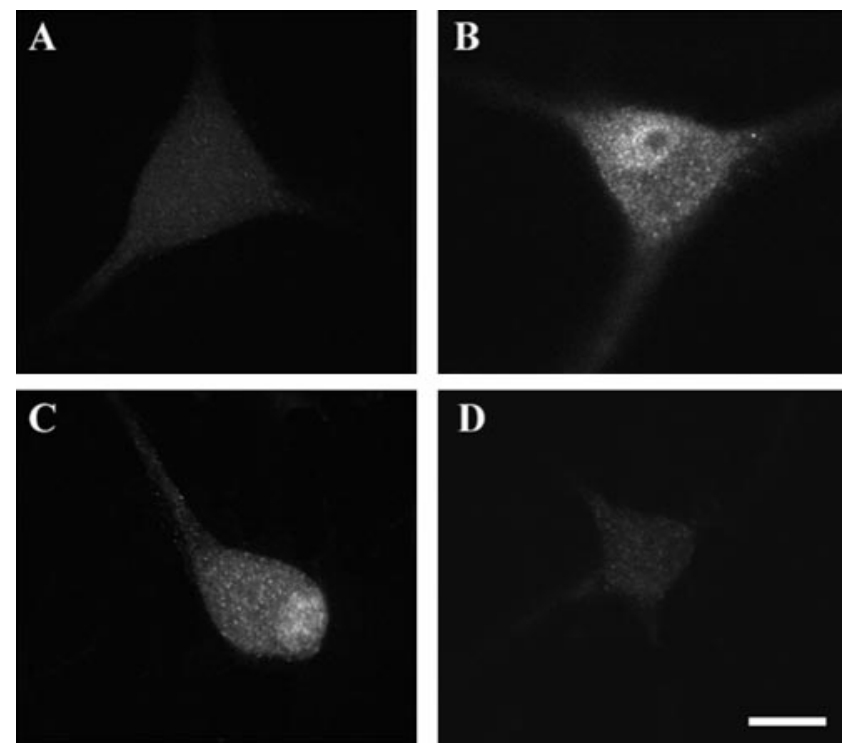

Figure 10. LIF and CNTF induce nuclear translocation of stat3. Cultures of sympathetic neurons were exposed to OP-1 $(50 \mathrm{ng} / \mathrm{ml})$ for $3 \mathrm{~d}(A)$ and then treated for $20 \mathrm{~min}$ with $30 \mathrm{ng} / \mathrm{ml} \mathrm{LIF}(B)$, CNTF $(C)$, or IL-6 $(D)$. Cultures were then fixed and immunostained with an antibody to phosphorylated forms of stat3. The subcellular localization of stat 3 was examined in a confocal microscope using $1 \mu \mathrm{m}$ optical sections. Scale bar, $50 \mu \mathrm{m}$.

lacking non-neuronal cells, indicating a direct effect of these agents on neurons. Moreover, dendritic retraction was not accompanied by changes in cell number, axonal growth, or the expression of axonal cytoskeletal elements. These data indicate that LIF and CNTF can modify cell shape in a highly selective manner and that they therefore have the potential to function as morphogens.

Dendritic growth has been studied extensively in sympathetic ganglia (Purves et al., 1988), and its regulation appears to be multifactorial. Previous studies have shown that OP-1 and related bone morphogenetic proteins induce dendritic growth in sympathetic neurons (Lein et al., 1995) and that NGF is required as a cofactor for this activity (Snider, 1988; Lein et al., 1995). In addition, there are at least two classes of molecules, neuropoietic cytokines (Guo et al., 1997) and retinoids (V. Chandrasekaran and D. Higgins, unpublished observations), that can inhibit the initial extension of these processes. The current study suggests an additional level of complexity in the regulation of the morphological development of these cells by demonstrating that there are also agents that can cause dendritic regression. The latter type of interaction could have profound effects on cell shape, and there is 
reason to believe that it may occur in vivo. Sweat glands secrete a CNTF-like molecule that determines the neurotransmitter phenotype of the sympathetic neurons projecting to this tissue, and the actions of this molecule are mimicked by LIF and CNTF (Patterson and Nawa, 1993; Patterson, 1994; Landis, 1996). Because the concentrations of neuropoietic cytokines required for dendritic retraction are similar to those eliciting changes in the synthesis of neurotransmitters, it is probable that sufficient sweat gland factor reaches the innervating neurons to alter their dendritic morphology. In addition, sympathetic neurons are also exposed to other sources of neuropoietic cytokines during normal development, including cardiotrophin-1 from the heart (Pennica et al., 1996), CNTF from glia (Ip and Yancopoulos, 1996), and an autocrine supply of LIF (Cheng and Patterson, 1997) and IL-6 (Marz et al., 1998).

Cytokine-induced dendritic retraction may also occur as part of the injury response of sympathetic neurons. Axotomy of superior cervical ganglion neurons leads to large and rapid increases in the synthesis of LIF (Banner and Patterson, 1994; Curtis et al., 1994; Sun et al., 1996) and IL-6 (Gadient and Otten, 1997), and the change in LIF expression is sufficient to induce changes in the neurotransmitter status of these neurons (Rao et al., 1993). Axotomy also causes dendritic retraction in sympathetic ganglia (Purves, 1975; Yawo, 1987). It is generally thought that this dendritic atrophy occurs because the injury deprives the neurons of their target-derived trophic factor, NGF (Purves et al., 1988). This idea is largely based on the observations that NGF deprivation causes dendritic atrophy (Ruit et al., 1990) and that administration of NGF reduces some of the effects of axotomy (Purves and Nja, 1976). However, it has not been directly demonstrated that NGF alters the effects of axotomy on dendritic retraction in sympathetic ganglia (Yawo et al., 1987). Our data suggest that there is an alternative or parallel pathway that can cause dendritic retraction. If this is the case, then injury-induced dendritic regression reflects not only separation from the target tissue but also the effects of pro-inflammatory cytokines. This proposition can be tested directly using transgenic mice lacking the LIF gene (Escary et al., 1993), and under these conditions it will be of interest to determine whether axotomy-induced dendritic retraction is also reduced in other neural populations, including spinal motor neurons (Sumner and Watson, 1971).

Dendritic regression occurs in many neurodegenerative diseases (Lambert et al., 1975; Takashima et al., 1989; Flood and Coleman, 1990; Patt et al., 1991: Masliah et al., 1997), and this is often associated with increased synthesis of neuropoietic cytokines (Patterson, 1994; Patterson, 1995; Gadient and Otten, 1997; Murphy et al., 1997). For example, IL-6 is markedly elevated in the nigrostriatal region of Parkinson's patients (Mogi et al., 1994), and it is also found in the $\beta$ amyloid plaques characteristic of Alzheimer's disease (Bauer et al., 1991; Strauss et al., 1992; Hull et al., 1996). It is possible, therefore, that neuropoietic cytokines contribute to the dendritic atrophy observed in neurodegenerative diseases. In this respect, it is important to note that the effects of neuropoietic cytokines are dominant, i.e., they cause dendritic retraction even in the presence of optimal concentrations of OP-1 and NGF. Moreover, their effects are not surmounted by increasing the concentration of either of these trophic factors (D. Higgins, unpublished data). If this is also true in vivo, this would mean that in some degenerative disorders, administration of neurotrophic factors by themselves may fail to reverse the dendritic atrophy and that adjunctive agents that interfere with the synthesis or activity of cytokines may be required (Carlson et al., 1996; Gadient and Otten, 1997).

Neuropoietic cytokines affect sympathetic neurons in a complex manner. They alter the proliferation and survival of these cells (Ernsberger et al., 1989), stimulate axonal sprouting (Thompson and Majithia, 1998), and induce changes in important aspects of their phenotype such as the neurotransmitter status (Patterson and Nawa, 1993; Landis, 1996) and expression of transmitter receptors (Mehler and Kessler, 1997). In addition, neuropoietic cytokines can exert regressive effects on sympathetic neurons by inhibiting dendritic growth and causing resorption of these processes (Guo et al., 1997). At certain stages of development, they also cause cell death (Kessler et al., 1993; Kotzbauer et al., 1994). Thus, neuropoietic cytokines resemble neurotrophins in that they have pleiotropic effects on sympathetic neurons. Neurotrophins use two classes of receptors: the trk proteins that have been found to have primarily trophic effects (Ip and Yancopoulos, 1996) and the $\mathrm{p} 75$ receptor that can exert either positive or negative effects, the latter including cell death (Carter and Lewin, 1997). It seemed important, therefore, to determine whether a single signaling pathway mediates both the trophic and regressive effects of the neuropoietic cytokines on sympathetic neurons.

Cultured sympathetic neurons have been shown to express major components of the gp130/stat pathway, including gp130, the LIFR, and the CNTFR (Wong et al., 1995), and strong evidence indicates that this pathway mediates the effects of cytokines on neurotransmitter status (Habecker et al.; 1997; Marz et al., 1998). On the other hand, evidence for the involvement of gp130/stat in regressive actions of these cytokines has derived primarily from the observation that CNTF-induced cell death was prevented by treatment with a phospholipase known to have the capacity to cleave the glycosylphosphatidylinositol linkage that attaches the CNTFR to the membrane (Kessler et al., 1993). Our experiments confirm this previous observation by demonstrating that phospholipase treatment also specifically blocks the effects of CNTF, but not LIF, on dendritic retraction. The fact that a single phospholipase treatment caused only a partial reversal of CNTF effects probably reflects the subsequent reappearance of a new CNTF receptor on the plasma membrane during the next $48 \mathrm{hr}$ in vitro, although this was not tested directly. However, subsequent experiments demonstrated that an antibody to gp130 blocks LIFinduced dendritic retraction, that the phosphorylation and nuclear translocation of stat 3 precede the morphological changes, and that exposure to soluble IL-6R endows IL-6 with the ability to induce process regression. Because the IL-6R is known to bind to gp130 (Taga et al., 1989; Mackiewicz et al., 1995), these observations strongly suggest that the gp130 pathway is involved in dendritic retraction.

In summary, our data identify a new activity of cytokines that activate the gp130 pathway and suggest that these mediators may function as neural morphogens. In addition, because dendrites are the primary site of synapse formation in vertebrates and because these agents cause their retraction, the data raise the possibility that neuropoietic cytokines could be involved in synapse elimination.

\section{REFERENCES}

Armengol JA, Sotelo C (1991) Early dendritic development of Purkinje cells in the rat cerebellum. A light and electron microscopic study using axonal tracing in "in vitro" slices. Dev Brain Res 64:95-114.

Banner LK, Patterson PH (1994) Major changes in the expression of the mRNAs for cholinergic differentiation factor/leukemia inhibitory factor 
and its receptor after injury to adult peripheral nerves and ganglia. Proc Natl Acad Sci USA 91:7109-7113.

Bauer J, Strauss S, Schreiter-Gasser U, Ganter U, Schlegel P, Witt I, Yolk B, Berger M (1991) Interleukin-6 and alpha-2 macroglobulin indicate an acute phase state in Alzheimer's disease cortices. FEBS Lett 285:111-114.

Carlson CD, Bai Y, Ding M, Jonakait GM, Hart RP (1996) Interleukin 1 involvement in the induction of leukemia inhibitory factor mRNA expression following axotomy of sympathetic ganglia. J Neuroimmunol 70:181-190.

Carter BD, Lewin GR (1997) Neurotrophins live or let die: does p75 ntr decide? Neuron 18:187-190.

Cheng JG, Patterson PH (1997) LIF is an autocrine factor for sympathetic neurons. Mol Cell Neurosci 9:372-380.

Curtis R, Scherer SS, Somogyi R, Adryan KM, Ip NY, Zhu Y, Lindsay RM, DiStephano PS (1994) Retrograde axonal transport of LIF is increased by peripheral nerve injury: correlation with increased LIF expression in distal nerve. Neuron 12:191-204.

Ernsberger U, Sendtner M, Rohrer H (1989) Proliferation and differentiation of embryonic chick sympathetic neurons: effects of ciliary neurotrophic factor. Neuron 2:1275-1284.

Escary J, Perreau J, Dumenil D, Ezine S, Brulet P (1993) Leukemia inhibitory factor is necessary for maintenance of haematopoietic stem cells and thymocyte stimulation. Nature 363:361-364.

Flood DG (1993) Critical issues in the analysis of dendritic extent in aging humans, primates, and rodents. Neurobiol Aging 14:649-654.

Flood DG, Coleman PD (1990) Hippocampal plasticity in normal aging and decreased plasticity in Alzheimer's disease. Prog Brain Res 83:435-443.

Gadient RA, Otten UH (1997) Interleukin-6(IL-6) - a molecule with both beneficial and destructive potentials. Prog Neurobiol 52:379-390.

Guo X, Metzler-Northrup J, Lein P, Rueger D, Higgins D (1997) Leukemia inhibitory factor and ciliary neurotrophic factor regulate dendritic growth in cultures of rat sympathetic neurons. Dev Brain Res 104:101-110.

Habecker BA, Symes AJ, Stahl N, Francis NJ, Economides A, Fink JS, Yancopoulous GD, Landis SC (1997) A sweat gland-derived differentiation activity acts through known cytokine signaling pathways. J Biol Chem 272:30421-30428.

Higgins D, Lein PJ, Osterhout DJ, Johnson MI (1991) Tissue culture of mammalian autonomic neurons. In: Culturing nerve cells, (Banker G, Goslin K, eds), pp 177-205. Cambridge, MA: MIT.

Hull M, Strauss S, Berger M, Volk B, Bauer J (1996) The participation of interleukin-6, a stress-inducible cytokine, in the pathogenesis of Alzheimer's disease. Behav Brain Res 78:37-41.

Ip NY, Yancopoulos GD (1996) The neurotrophins and CNTF: two families of collaborative neurotrophic factors. Annu Rev Neurosci 19:491-515.

Jhaveri S, Morest DK (1982) Sequential alterations of neuronal architecture in nucleus magnocellularis of the developing chicken: a Golgi study. Neuroscience 7:837-853.

Kessler JA, Ludlam WH, Freidin MM, Hall DH, Michaelson MD, Spray DC, Dougherty M, Batter DK (1993) Cytokine-induced programmed death of cultured sympathetic neurons. Neuron 11:1123-1132.

Koester SE, O'Leary DD (1992) Functional classes of cortical projection neurons develop dendritic distinctions by class-specific sculpting of an early common pattern. J Neurosci 12:1382-1393.

Kotzbauer PT, Lampe PA, Estus S, Milbrandt J, Johnson EM Jr (1994) Postnatal development of survival responsiveness in rat sympathetic neurons to leukemia inhibitory factor and ciliary neurotrophic factor. Neuron 12:763-773.

LaFont F, Prochiantz A, Valenza C, Peititou M, Pascal M, Rouget M, Rousselet A (1994) Defined glycosaminoglycan motifs have opposite effects on neuronal polarity in vitro. Dev Biol 162:453-468.

Lambert PW, Gajdusek DC, Gibbs Jr CJ (1975) Pathology of dendrites in subacute spongiform virus encephalopathies. Adv Neurol 12:465-470.

Landis SC (1996) The development of cholinergic sympathetic neurons: a role for neuropoietic cytokines. Perspect Dev Neurobiol 4:53-63.

Landmesser L, Pilar G (1974) Synapse formation during embryogenesis on ganglion cells lacking a periphery. J Physiol (Lond) 241:715-736.

Lein P, Johnson M, Guo X, Rueger D, Higgins D (1995) Osteogenic protein-1 induces dendritic growth in rat sympathetic neurons. Neuron 15:597-605.

Leuba G, Garey LJ (1984) Development of dendritic patterns in the lateral geniculate nucleus of monkey: a quantitative Golgi study. Brain Res 318:285-299.

Luo Y, Raper J (1994) Inhibitory factors controlling growth cone motility and guidance. Curr Opin Neurobiol 4:648-654.

Mackiewicz A, Wiznerowicz M, Roeb E, Karczewska A, Nowak J, Heinrich PC, Rose-John S (1995) Soluble interleukin 6 receptor is biologically active in vivo. Cytokine 7:142-149.

Marz P, Chen JG, Gadient RA, Patterson PH, Stoyan T, Otten U, Rose-John S (1998) Sympathetic neurons can produce and respond to interleukin 6. Proc Natl Acad Sci USA 95:3251-3256.

Masliah E, Heaton R, Marcotte TD, Ellis, RJ, Wiley CA, Mallory M, Achim CL, McCutchan JA, Nelson JA, Atkinson JH, Grant I, the HNRC Group (1997) Dendritic injury is a pathological substrate for human immunodeficiency virus-related cognitive disorders. Ann Neurol 42:963-972.

Mattson MP (1988) Neurotransmitters in the regulation of neuronal cytoarchitecture. Brain Res Rev 13:179-212.

McAllister AK, Katz LC, Lo DC (1997) Opposing roles for endogenous BDNF and NT-3 in regulating cortical dendritic growth. Neuron 18:767-778.

McEwen BS, Magarinos AM (1997) Stress effects on morphology and function of the hippocampus. Ann NY Acad Sci 821:271-284.

Mehler MF, Kessler JA (1997) Hematolymphopoietic and inflammatory cytokines in neural development. Trends Neurosci 20:357-365.

Metzger F, Wiese, S, Sendtner M (1998) Effect of glutamate on dendritic growth in embryonic rat motoneurons. J Neurosci 18:1735-1742.

Mogi M, Harada M, Kondo T, Riederer P, Inagaki H, Minami M, Nagatsu $\mathrm{T}$ (1994) Interleukin $1 \beta$, interleukin-6, epidermal growth factor and transforming growth factor- $\alpha$ are elevated in the brain from Parkinsonian patients. Neurosci Lett 180:147-150.

Murphy M, Dutton R, Koblar S, Cheema S, Bartlett P (1997) Cytokines which signal through the LIF receptor and their actions in the nervous system. Prog Neurobiol 52:355-378.

Patt S, Gertz THJ, Gerhard L, Cervos-Navarro J (1991) Pathological changes in dendrites of substantia nigra neurons in Parkinson's disease: a Golgi study. Histol Histopathol 6:373-380.

Patterson PH (1994) Leukemia inhibitory factor, a cytokine at the interface between neurobioloby and immunology. Proc Natl Acad Sci USA 91:7833-7835.

Patterson PH (1995) Cytokines in Alzheimer's disease and multiple sclerosis. Curr Opin Neurobiol 5:642-646.

Patterson PH, Nawa H (1993) Neuronal differentiation factors/cytokines and synaptic plasticity. Cell 72:123-137.

Pennica D, Wood WI, Chien KR (1996) Cardotrophin-1: a multifunctional cytokine that signals via LIF receptor-gp130 dependent pathways. Cytokine Growth Factor Rev 7:81-91.

Purves D (1975) Functional and structural changes in mammalian sympathetic neurons following interruption of their axons. J Physiol (Lond) 252:429-463.

Purves D, Nja A (1976) Effect of nerve growth factor on synaptic depression after axotomy. Nature 260:535-536.

Purves D, Snider W, Voyvodic JT (1988) Trophic regulation of nerve cell morphology and innervation in the autonomic nervous system. Nature 336:123-128.

Rao MS, Sun Y, Escary JL, Perreau J, Tresser S, Patterson PH, Zigmond RE, Brulet P, Landis SC (1993) Leukemia inhibitory factor mediates an injury response but not a target-directed developmental transmitter switch in sympathetic neurons. Neuron 11:1175-1185.

Rihn LL, Claiborne BJ (1990) Dendritic growth and regression in rat dentate granule cells during late postnatal development. Dev Brain Res 54:115-124.

Ruit KG, Osborne PA, Schmidt RE, Johnson EM, Snider WD (1990) Nerve growth factor regulates sympathetic ganglion cell morphology and survival in the adult mouse. J Neurosci 10:2412-2419.

Saito T, Yasukawa K, Suzuki H, Futatsugi K, Fukunaga T, Yokomizo C, Fukui H, Ohsugi Y, Yawata H (1991) Preparation of soluble murine IL-6 receptor and anti-murine IL-6 receptor antibodies. J Immunol 147:168-173.

Sampath TK, Maliakal JC, Hauschka PV, Jones WK, Sasak H, Tucker RK, White KH, Coughlin JE, Tucker MM, Pang RHL, Corbett C, Ozkaynak E, Oppermann H, Rueger D (1992) Recombinant human osteogenic protein-1 (hOP-1) induces new bone formation in vivo with a specific activity comparable with natural bovine osteogenic protein and stimulates osteoblast proliferation and differentiation in vitro. J Biol Chem 267:20352-20362. 
Segal RA, Greenberg ME (1996) Intracellular signaling pathways activated by neurotrophic factors. Annu Rev Neurosci 19:463-489.

Snider WD (1988) Nerve growth factor enhances dendritic arborization of sympathetic ganglion cells in developing mammals. J Neurosci $8: 2628-2634$

Snider WD, Lichtman JW (1996) Are neurotrophins synaptotrophins? Mol Cell Neurosci 7:433-442.

Strauss S, Bauer J, Ganter U, Jonas U, Berger M, Volk B (1992) Detection of interleukin- 6 and $\alpha 2$-macroglobulin immunoreactivity in cortex and hippocampus of Alzheimer's disease patients. Lab Invest 66:223-230.

Sumner BE, Watson WE (1971) Retraction and expansion of the dendritic tree of motor neurones of adult rats induced in vivo. Nature 233:273-275.

Sun YS, Landis SC, Zigmond R (1996) Signals triggering the induction of leukemia inhibitory factor in sympathetic superior cervical ganglia and their nerve trunks after axonal injury. Mol Cell Neurosci 7:152-163.

Taga T, Higi M, Hirata Y, Kamasaki K, Yasukawa K, Matsuda T, Hirano
T, Kishimoto T (1989) Interleukin-6 triggers the association of its receptor with a possible signal transducer, gp130. Cell 58:573-581.

Takashima S, Ieshima A, Nakamura H, Becker LE (1989) Dendrites, dementia and the Down Syndrome. Brain Dev 11:131-133.

Tessier-Lavigne M, Goodman CS (1996) The molecular biology of axon guidance. Science 274:1123-1133.

Thompson SWN, Majithia AA (1998) Leukemia inhibitory factor induces sympathetic sprouting in intact dorsal root ganglia in the adult rat in vivo. J Physiol (Lond) 506:809-816.

Wong V, Pearsall D, Arriaga R, Ip NY, Stahl N, Lindsay RM (1995) Binding characteristics of ciliary neurotrophic factor to sympathetic neurons and neuronal cell lines. J Biol Chem 270:313-318.

Yawo H (1987) Changes in the dendritic geometry of mouse superior cervical ganglion cells following postganglionic axotomy. J Neurosci 7:3703-3711.

Zigmond RE, Hyatt-Sachs H, Mohney RP, Schreiber RC, Shadiack AM, Sun Y, Vaccariello SA (1996) Changes in neuropeptide phenotype after axotomy of adult peripheral neurons and the role of leukemia inhibitory factor. Perspect Dev Neurobiol 4:75-90. 